\title{
Does Autoimmunity Play a Role in the Immunopathogenesis of Vasculitis Associated With Chronic Chagas Disease?
}

\author{
Victor Garcia-Bustos ${ }^{1 *}$, Pedro Moral Moral ${ }^{1}$, Marta Dafne Cabañero-Navalon ${ }^{1}$, \\ Miguel Salavert Lletí ${ }^{1}$ and Eva Calabuig Muñoz ${ }^{1,2}$ \\ ${ }^{1}$ Department of Internal Medicine and Infectious Diseases, University and Polytechnic La Fe Hospital, Valencia, Spain, \\ 2 Department of Medicine, University of Valencia, Valencia, Spain
}

Keywords: Chagas, Trypanosoma cruzi, vasculitis, autoimmunity, immunopathology

OPEN ACCESS

Edited by:

Andréa Teixeira-Carvalho, René Rachou Institute (Fiocruz), Brazil

Reviewed by:

Fernanda Fortes De Araújo, René Rachou Institute (Fiocruz), Brazil

Marisa Mariel Fernandez,

Institute of Studies on Humoral Immunity (IDEHU), Argentina

${ }^{*}$ Correspondence:

Victor Garcia-Bustos

victorgarciabustos@gmail.com

Specialty section: This article was submitted to

Parasite and Host,

a section of the journal

Frontiers in Cellular and

Infection Microbiology

Received: 24 February 2021

Accepted: 18 June 2021

Published: 06 July 2021

Citation:

Garcia-Bustos V, Moral Moral P,

Cabañero-Navalon MD,

Salavert Lletí M and Calabuig Muñoz E (2021) Does Autoimmunity Play a

Role in the Immunopathogenesis of

Vasculitis Associated With

Chronic Chagas Disease?

Front. Cell. Infect. Microbiol. 11:671962.

doi: 10.3389/fcimb.2021.671962

\section{INTRODUCTION}

Chagas disease $(\mathrm{CD})$ is a chronic systemic vector-borne infection caused by the protozoan Trypanosoma cruzi. It has spread from Latin America through migration, becoming a global issue (Pérez-Molina and Molina, 2018). Its prevalence is $\sim 7$ million people worldwide, of whom 30$40 \%$ will develop severe chronic complications such as cardiomyopathy or megaviscerae, with a considerable impact on morbimortality (WHO, 2020; WHO, 2021).

The parasite is transmitted after metacyclic trypomastigotes in the feces of a triatomine insect enter the host through the bite wound. They penetrate cells and transform into amastigotes, where they multiply by binary fission and differentiate again into circulating trypomastigotes after rupture of the host cell. The triatomine vector ingests them from an infected individual and they replicate in its intestine in the form of epimastigotes. The cycle closes after the epimastigotes differentiate again into metacyclic trypomastigotes (Pérez-Molina and Molina, 2018).

Chronic clinical manifestations in $\mathrm{CD}$ have been associated with a disproportionate inflammation compared to the parasitic burden (Cunha-Neto et al., 2011), driven by direct parasitic invasiveness (Bonney and Engman, 2008; Epting et al., 2010), damage to bystander cells (De Bona et al., 2018), cellular injury due to non-specific immune responses (Bellotti et al., 1996; Zhang and Tarleton, 1999; Bonney and Engman, 2015; De Bona et al., 2018), autoimmunity (Leon et al., 2001; Engman and Leon, 2002; Bonney and Engman, 2015; De Bona et al., 2018), and vasculitis (Roffê et al., 2016; Weaver et al., 2019).

Herein, we review the autoimmune mechanisms behind chronic CD and, particularly, the knowledge gaps in the immunopathogenesis of vasculitis developed in patients with CD.

\section{WHAT WE KNOW ABOUT AUTOIMMUNITY IN CHRONIC CHAGAS DISEASE}

Since the first insights into the pathophysiology of CD, autoimmunity has been attributed a potential key role in the development of chronic complications of the disease. The scarcity of viable parasites in chronic Chagas cardiomyopathy (CCC) contrasts with the severity of the disease 
(Cunha-Neto et al., 2011). Some studies have not found a correlation between the parasitic burden and the degree of tissue inflammation (Dias et al., 1956; Todorov et al., 2003). The identification of a relatively large number of autoantibodies, autoreactive T cells, and myocardial specific antigens as targets of autoreactive responses (Rizzo et al., 1989; Leon et al., 2001; Engman and Leon, 2002) suggests that the immune response is not completely pathogen-specific. However, despite the presence of diverse autoimmunity processes has been extensively described in several studies, their pathogenic role has yet to be clarified.

The current autoimmune hypothesis suggests that the initial parasite-triggered cardiac damage leads to a release of selfantigens within an inflammatory environment (Engman and Leon, 2002), which leads to a breakdown of self-tolerance as a consequence of the potent immune stimuli. Owing to molecular mimicry between parasite and host protein epitopes within the microinflammatory environment caused by parasitic invasion (Cunha-Neto et al., 1996), polyclonal B cell and bystander activation (De Bona et al., 2018) and cross-activation of autoreactive $\mathrm{T}$ or $\mathrm{B}$ cells to host proteins is produced (Iwai et al., 2005). This triggers the synthesis of autoantibodies targeted to multiple antigens (De Bona et al., 2018). The parasite persistence in chronic stages of the infection causes a certain degree of myocytolysis and oxidative stress (Wen et al., 2004). Furthermore, toxin and bioactive lipids release, microvascular changes, and $\mathrm{T}$ cell-mediated delayed-type hypersensitivity, perpetuate the damage and the immune vicious circle (Leon et al., 2001; Engman and Leon, 2002; Bonney and Engman, 2015). Recently, important local structural and functional alterations have been described as a consequence of thymic infection by $T$. cruzi, which produces abnormal thymocyte migration and a disrupted negative selection of the T-cell repertoire (Pérez et al., 2020). Secondarily, abnormal activated double-positive and double-negative lymphocytes with a proinflammatory phenotype have been found in patients with $\mathrm{CD}$. This has been proposed to contribute to dysimmunity as a pathogenic determinant of chronic T. cruzi cardiac infection (Morrot et al., 2011; Flávia Nardy et al., 2015; Passos et al., 2017).

Several T. cruzi antigens have been demonstrated to crossreact with human molecules and generate autoantibodies that may be implicated in CCC, as seen in Table 1. Furthermore, in patients with CCC, the presence of anti- $\beta 1$-adrenergic receptors and anti-M2 receptors has been associated with progression (Retondaro et al., 1999; Labovsky et al., 2007); and, in the last, to electrical instability and sudden death (Medei et al., 2007). The existence a robust autoreactive $\mathrm{T}$ cell reaction feeds back the production of autoantibodies and suggests that autoimmune and dysimmune processes play a significant role in the pathogenesis.

Inflammatory responses mediated both by T CD4+ and CD8+ cells (Tarleton, 2001; Cunha-Neto et al., 2011), antibodydependent cell-mediated cytotoxicity (ADCC) (Bonney and Engman, 2008) and complement activation with formation of the membrane attack complex (MAC) (Aiello et al., 2002) are proposed factors for autoimmune-induced cell damage. After bystander activation and release of proinflammatory cytokines and mediators (such as tumor necrosis factor (TNF), interferongamma (IFN- $\gamma$ ), bradykinin, prostaglandins, endothelin, or nitric oxide, among other) and reactive oxygen species (ROS) by cells of the innate immune system, these specific autoantibodies interact with neutrophils, eosinophils, and NK cells via CD16, and perforins, proteolytic enzymes or TNF are released (De Bona et al., 2018). Furthermore, the complement system becomes activates and the MAC is assembled on cardiomyocytes and endothelial cells, which result in muscle injury and vasculitis (Aiello et al., 2002). Interestingly, significantly increased levels of circulating activated $\mathrm{T}$ cells and CD5+ B cells have been found in patients with CCC. This pattern has also been described in patients with rheumatoid arthritis and multiple sclerosis, where autoimmune, polyclonal and hyperimmune responses are responsible for the pathogeny of the disease (Dutra et al., 1994).

However, whether autoimmunity is determinant for the pathophysiology of chronic complications of the disease or is just an epiphenomenon is not clear. Some studies advocate the idea that autoimmune responses may be present in absence of inflammation, or be a consequence and not a cause of tissue injury (Leon and Engman, 2003). Others state pathogen-specific type 1 immune responses and not autoimmunity could be related to tissue injury (Roffê et al., 2016), and many keep the debate and controversy about the autoimmune hypothesis due to experimental limitations, low result reproducibility, and lack of persuasive evidence that autoreactive responses truly effect the observed injury in the multifaceted pathogeny of CCC (Levin, 1996; Kierszenbaum, 2003; Girones et al., 2007; Bonney and Engman, 2008; Tanowitz et al., 2009; Cunha-Neto et al., 2011). Interestingly, some of the antigens which have shown cross-

TABLE 1 | Cross-reactivity between T. cruzi and human antigens with possible implications in Chagasic cardiomyopathy.

\begin{tabular}{|c|c|c|}
\hline Trypanosoma cruzi antigen & Human antigen & Reference \\
\hline Glycosphingolipids & Neutral glycosphingolipids & Vermelho et al., 1997 \\
\hline Cruzipain & Cardiac muscarinic acetylcholine receptors (M2) & Goin et al., 1999; Acosta et al., 2011 \\
\hline 23KDa ribosomal protein & Ribosomal P protein & Bonfa et al., 1993; Kaplan et al., 1997 \\
\hline $\begin{array}{l}\text { Sarcoplasmic reticulum adenosine- } \\
\text { triphosphatase (SRA) }\end{array}$ & SRA of cardiomyocytes and skeletal muscle myocytes & Santos-Buch et al., 1985 \\
\hline Microsomal fraction (Mc) & Cha autoantigen & Laucella et al., 1996 \\
\hline Shed acute-phase antigen (SAPA) & Galectin-1 & Giordanengo et al., 2001 \\
\hline Ribosomal P0 and P2 $\beta$ proteins & Cardiac $\beta 1$ adrenergic receptor & $\begin{array}{l}\text { Labovsky et al., 2007; Abraham and Derk, 2015; Jiménez } \\
\text { et al., } 2017\end{array}$ \\
\hline B13 protein & Cardiac myosin heavy chain & Cunha-Neto et al., 1996 \\
\hline
\end{tabular}


reactivity with human epitopes, such as cruzipain as the most important one, are candidates for vaccine against $T$. cruzi (Bivona et al., 2020). Despite vaccine promotion was limited for years because of the possibility to induce autoimmunity, posterior evidence suggested autoimmunity as a consequence of parasite persistence and prioritized the parasite clearance to avoid it (Bonney and Engman, 2015; Bivona et al., 2020). In fact, immunization with different cruzipain analogues has demonstrated protective immunity without causing cardiac abnormalities (Cazorla et al., 2015).

\section{VASCULITIS IN THE PATHOPHYSIOLOGY OF CHRONIC CHAGAS DISEASE: THE GREAT FORGOTTEN?}

Different pathogenic mechanisms have been described to explain the large variability in the clinical outcome of T. cruzi infection. In addition to direct parasite damage (Bonney and Engman, 2008; Epting et al., 2010), bystander effect (De Bona et al., 2018), autoimmunity (Leon et al., 2001; Engman and Leon, 2002; Bonney and Engman, 2015; De Bona et al., 2018), and nonspecific immune responses (Bellotti et al., 1996; Zhang and Tarleton, 1999; Bonney and Engman, 2015; De Bona et al., 2018), the presence of vasculitis in chronic CD has long been reported. However, contrarily to the previous factors, the immune mechanisms driving vasculitis and its pathogenic implications have hardly been studied.

T. cruzi infection has been found to cause vasculitis, perivascular inflammation, vascular necrosis, and endothelitis affecting both macrovasculature and microvasculature of several organs and tissues (Dias et al., 1956; Okumura et al., 1960; Cossermelli et al., 1978; Sunnemark et al., 1998; Petkova et al., 2001; Tanowitz et al., 2009; Prado et al., 2011; Roffê et al., 2016; Weaver et al., 2019). Coronary vessels (Petkova et al., 2000; Petkova et al., 2001), aorta (Petkova et al., 2000; Petkova et al., 2001, liver (Mukherjee et al., 2003), skeletal muscle (Roffê et al., 2016; Weaver et al., 2019), and nerves blood vessels (Said et al., 1985; González Cappa et al., 1987) are involved as demonstrated by studies in several animal models, including mice, pigs, and dogs. Recent works in murine models have demonstrated that its implication in the pathogeny of T. cruzi infection might be determinant, with low-level parasite persistence driving severe paralyzing systemic necrotizing vasculitis (Roffê et al., 2016; Weaver et al., 2019).

In humans, the first description of vasculitis was in 1911 (Vianna, 1911). Cerebral vasculitis (Petkova et al., 2001), muscle vasculitis (Laguens et al., 1975; Cossermelli et al., 1978), and obliterative coronary vasculitis (Dias et al., 1956) have been reported. Moreover, recently, our group published the first case of a patient with anti-neutrophil cytoplasmic antibody-positive (ANCA) vasculitis and chronic CD (Garcia-Bustos et al., 2020a). This case was also a highly atypical presentation of ANCAassociated vasculitis, as presented with periaortitis, possibly due to vasa vasorum vasculitis, and muscle vasculitis, as described in the murine model. This again raises the dilemma of the pathophysiology of vasculitis in chronic CD and the potential role and implication of autoimmunity in its development.

Some studies reported endothelial invasion by amastigotes of T. cruzi in the very early stages of infection, even before parasitemia occurs (Factor et al., 1985). However, this does not explain the inflammatory involvement of many vascular beds in the late stages of the disease when the parasite burden is practically non-existent. Nevertheless, parasitic endothelial invasion has been demonstrated to induce expression of proinflammatory cytokines, nitric oxidase synthases, and adhesion molecules (Tanowitz et al., 1992; Sunnemark et al., 1998; Campos-Estrada et al., 2015). Some vasoactive mediators such as bradykinin, endothelin-1, and thromboxane A2 (Prado et al., 2011; Garcia-Bustos et al., 2020b) have also been implicated in the inflammatory process. These findings would make us hypothesize whether the interaction between the endothelium and effector immune cells within an inflammatory environment may induce bystander activation mechanisms, molecular mimicry, and development of autoreactive $\mathrm{T}$ cells and antibodies.

Despite the many advances made in the cellular and molecular immune mechanisms of chronic CD during the 80s and 90s, only recently have we been able to know the first glimpses of the immunological mechanisms underlying the development of Chagas vasculitis. In a murine model, Roffê, Weaver, and coworkers (2016 and 2019, respectively) described systemic necrotizing vasculitis with histological findings resembling human polyarteritis nodosa (PAN), with skeletal muscle arteries being the most severely affected. The presence of large inflammatory infiltrates composed by F4/80+ myeloid cells and T. cruzi tetramer-specific CD8+ T lymphocytes producing tumor necrosis factor-alpha (TNF- $\alpha$ ), interferon-gamma (IFN- $\gamma$ ) but not interleukin 17 (IL-17) without neutrophils or immune complexes, advocates for a pathogen-specific type 1 immune response and not autoimmunity as the pathogenic mechanism. In concordance with other findings (González Cappa et al., 1987), no parasites were observed, so the severity of vasculitis is highly disproportionate to the low parasite burden. Hence, whether the recruitment of autoreactive responses after a parasite-induced breakdown of self-tolerance triggers or contributes to the Chagas vasculitis immunopathology is yet to be determined.

\section{AUTOIMMUNITY AND CHAGAS VASCULITIS. WHAT IF...?}

There is a large variability in the outcomes of $\mathrm{CD}$ due to its possibility to infect several hosts and diverse behavior within, parasite diversity, and different immunopathogenic mechanisms of disease (De Bona et al., 2018). In the same way, different vasculitis patterns have been described both in animal models and humans associated with CD.

Primary systemic vasculitides have been traditionally classified according to the main vessels' caliber involved: largevessel, such as giant cell arteritis or Takayasu arteritis; mediumvessel, such as PAN or Kawasaki disease, and small-vessel 
vasculitides. The latter can be subdivided into ANCA-associated vasculitis (AAV) and immune complex small vessel vasculitis (Shavit et al., 2018). Their pathogenesis is complex and diverse, and genetic and immunological determinants have been identified (Ozen and Batu, 2018). However, a key feature of AAV which is not present in other vasculitides is the presence of ANCA directed against myeloperoxidase (MPO) or proteinase-3 (PR3), which are determinants for their pathogenesis (Leacy et al., 2020). In CD, many vascular beds are affected, with histology mainly showing mononuclear and macrophage infiltration, fibrinoid necrosis, and necrotizing vasculitis (Petkova et al., 2001; Roffê et al., 2016; Weaver et al., 2019).

In humans, Laguens et al. (1975) described immunoglobulins bound to the plasma membrane of both muscle fibers and endothelial cells in muscle biopsies of patients with CD. Similarly, Cossermelli et al. (1978) reported perivascular mononuclear infiltrate with deposition of IgM and C3 in the arterial wall in a patient with muscle vasculitis. Necrotizing arteritis has been reported in arteries of patients with megaesophagus (Brito and Vasconcelos, 1959), similar to that reported in mice by Roffê (Roffê et al., 2016; Weaver et al., 2019) and findings in PAN (Ozen, 2017). Our case, nonetheless, is the only one in the literature showing an AAV with autoantibodies against myeloperoxidase with documented presence of aortitis, muscle vasculitis, and probable renal involvement (Garcia-Bustos et al., 2020a). Mainly all reports share in common the predominance of mononuclear and macrophage cells, fibrinoid necrosis, and, in some cases, necrotizing vasculitis (Dias et al., 1956; Okumura et al., 1960; Cossermelli et al., 1978; Sunnemark et al., 1998; Petkova et al., 2001; Tanowitz et al., 2009; Prado et al., 2011; Roffê et al., 2016; Weaver et al., 2019). The organ involvement partially mimics that of medium and small vessel primary systemic vasculitides, including $\mathrm{PAN}$ or, to a lesser extent, AAV. However, there is a disagreement between human and animal studies on the importance of autoantibodies or the role of immune complexes.

As we can see, evidence on Chagas vasculitis immunopathogenesis is scarce and practically absent in humans. The role of autoreactive responses or autoantibodies is, hence, yet to be

\section{REFERENCES}

Abraham, M., and Derk, C. T. (2015). Anti-Ribosomal-P Antibodies in Lupus Nephritis, Neuropsychiatric Lupus, Lupus Hepatitis, and Chagas' Disease: Promising Yet Limited in Clinical Utility. Rheumatol. Int. 35, 27-33. doi: 10.1007/s00296-014-3058-3

Acosta, D. M., Soprano, L. L., Ferrero, M., Landoni, M., Esteva, M. I., Couto, A. S., et al. (2011). A Striking Common O-Linked N-Acetylglucosaminyl Moiety Between Cruzipain and Myosin. Parasit. Immunol. 33, 363-370. doi: 10.1111/ j.1365-3024.2011.01291.x

Aiello, V. D., Reis, M. M., Benvenuti, L. A., De Higuchi, M. L., Ramires, J. A. F., and Halperin, J. A. (2002). A Possible Role for Complement in the Pathogenesis of Chronic Chagasic Cardiomyopathy. J. Pathol. 197, 224-229. doi: 10.1002/path.1095

Bellotti, G., Bocchi, E. A., de Moraes, A. V., Higuchi, M. L., Barbero- Marcial, M., Sosa, E., et al. (1996). In Vivo Detection of Trypanosoma Cruzi Antigens in Hearts of Patients With Chronic Chagas' Heart Disease. Am. Heart J. 131, 301e307. doi: 10.1016/s0002-8703(96)90358-0

Bivona, A. E., Alberti, A. S., Cerny, N., Trinitario, S. N., and Malchiodi, E. L. (2020). Chagas Disease Vaccine Design: The Search for an Efficient determined. Interestingly, one study found that cutaneous vasculitis in patients with systemic lupus erythematosus (SLE) was significantly associated with the presence of anti-ribosomal $\mathrm{P}$ protein antibodies (Shinjo and Bonfá, 2011), a commonly found autoantibody in patients with chronic CD (Mesri et al., 1990; Bonfa et al., 1993; Kaplan et al., 1997; Abraham and Derk, 2015). To date, this is the only common autoantibody in vasculitis and $\mathrm{CD}$, which makes us hypothesize about its implications in the pathogeny of vasculitis associated with chronic infection by $T$. cruzi, especially after immunoglobulin deposits have been found in the vascular walls of affected patients.

\section{CONCLUSIONS}

During the $80 \mathrm{~s}$ and $90 \mathrm{~s}$, the role of autoimmunity in the pathophysiology of chronic CD was deeply studied. Whilst it is indisputable that autoimmune responses are present in patients with chronic T. cruzi infection mainly due to bystander activation and molecular mimicry, whether they play a key role in its pathogeny is still controversial. Vasculitis of many vascular beds is also present in these patients. However, there are practically no data on the immune processes triggering its development and we do not know if autoimmunity is present. Further studies are needed to characterize vasculitis in patients with $\mathrm{CD}$ and explore its underlying immune cellular and molecular pathways.

\section{AUTHOR CONTRIBUTIONS}

VG-B conceived the idea, searched the bibliographic materials, reviewed the existing literature, and wrote the article. MC-N aided in the search of the bibliographic materials and contributed to the writing of the article. PM, MS, and EC reviewed the literature and contributed to the writing of the article. EC supervised the work. All authors contributed to the article and approved the submitted version.

Trypanosoma Cruzi Immune-Mediated Control. Biochim. Biophys. Acta Mol. Basis Dis. 1866, 165658. doi: 10.1016/j.bbadis.2019.165658

Bonfa, E., Viana, V. S., Barreto, A. C., Yoshinari, N. H., and Cossermelli, W. (1993). Autoantibodies in Chagas' Disease. An Antibody Cross-Reactive With Human and Trypanosoma Cruzi Ribosomal Proteins. J. Immunol. 150, 3917-3923.

Bonney, K. M., and Engman, D. M. (2008). Chagas Heart Disease Pathogenesis: One Mechanism or Many? Curr. Mol. Med. 8, 510-518. doi: 10.2174/ 156652408785748004

Bonney, K. M., and Engman, D. M. (2015). Autoimmune Pathogenesis of Chagas Heart Disease: Looking Back, Looking Ahead. Am. J. Pathol. 2015. 185, $1537-$ 1547. doi: 10.1016/j.ajpath.2014.12.023

Brito, T., and Vasconcelos, E. (1959). Necrotizing Arteritis in Megaesophagus. Histopathology of Ninety-One Biopsies Taken From the Cardia. Rev. Inst. MedTrop. Sao Paulo. 1, 195-206.

Campos-Estrada, C., Liempi, A., González-Herrera, F., Lapier, M., Kemmerling, U., Pesce, B., et al. (2015). Simvastatin and Benznidazole-Mediated Prevention of Trypanosoma Cruzi-Induced Endothelial Activation: Role of 15-EpiLipoxin A4 in the Action of Simvastatin. PloS Negl. Trop. Dis. 9, e0003770. doi: 10.1371/journal.pntd.0003770 
Cazorla, S. I., Matos, M. N., Cerny, N., Ramirez, C., Alberti, A. S., Bivona, A. E., et al. (2015). Oral Multicomponent DNA Vaccine Delivered by Attenuated Salmonella Elicited Immunoprotection Against American Trypanosomiasis. J. Infect. Dis. 211, 698-707. doi: 10.1093/infdis/jiu480

Cossermelli, W., Friedman, H., Pastor, E. H., Nobre, M. R., Manzione, A., Comargo, M. E., et al. (1978). Case Report Polymyositis in Chagas's Disease. Ann. Rheum. Dis. 37, 277-280. doi: 10.1136/ard.37.3.277

Cunha-Neto, E., Coelho, V., Guilherme, L., Fiorelli, A., Stolf, N., and Kalil, J. (1996). Autoimmunity in Chagas' Disease. Identification of Cardiac MyosinB13 Trypanosoma Cruzi Protein Crossreactive T Cell Clones in Heart Lesions of a Chronic Chagas' Cardiomyopathy Patient. J. Clin. Invest. 98, 1709-1712. doi: $10.1172 / \mathrm{JCI} 118969$

Cunha-Neto, E., Teixeira, P. C., Nogueira, L. G., and Kalil, J. (2011). Autoimmunity. Adv. Parasitol. 76, 129-152. doi: 10.1016/B978-0-12-385895-5.00006-2

De Bona, E., Lidani, K. C. F., Bavia, L., Omidian, Z., Gremski, L. H., Sandri, T. L., et al. (2018). Autoimmunity in Chronic Chagas Disease: A Road of Multiple Pathways to Cardiomyopathy? Front. Immunol. 9, 1842. doi: 10.3389/ fimmu.2018.01842

Dias, E., Laranja, F. S., Miranda, A., and Nobrega, G. (1956). Chagas' Disease; A Clinical, Epidemiologic, and Pathologic Study. Circulation 14, 1035-1060. doi: 10.1161/01.CIR.14.6.1035

Dutra, W. O., Martins-Filho, O. A., Cançado, J. R., Pinto-Dias, J. C., Brener, Z., Freeman Júnior, G. L., et al. (1994). Activated T and B Lymphocytes in Peripheral Blood of Patients With Chagas' Disease. Int. Immunol. 6, 499-506. doi: 10.1093/intimm/6.4.499

Engman, D. M., and Leon, J. S. (2002). Pathogenesis of Chagas Heart Disease: Role of Auto- Immunity. Acta Trop. 81, 123-132. doi: 10.1016/S0001-706X(01)00202-9

Epting, C. L., Coates, B. M., and Engman, D. M. (2010). Molecular Mechanisms of Host Cell Invasion by Trypanosoma Cruzi. Exp. Parasitol. 126, 283-291. doi: 10.1016/j.exppara.2010.06.023

Factor, S. M., Cho, S., Wittner, M., and Tanowitz, H. (1985). Abnormalities of the Coronary Microcirculation in Acute Murine Chagas' Disease. Am. J. Trop. Med. Hyg. 34, 246-253. doi: 10.4269/ajtmh.1985.34.246

Flávia Nardy, A., Santos, L., Freire-de-Lima, C. G., and Morrot, A. (2015). Modulation of Intrathymic Sphingosine-1-Phosphate Levels Promotes Escape of Immature Thymocytes to the Periphery With a Potential Proinflammatory Role in Chagas Disease. BioMed. Res. Int. 2015:709846. doi: 10.1155/2015/709846

Garcia-Bustos, V., Calabuig, E., López-Aldeguer, J., and Moral Moral, P. (2020a). Anti-Neutrophil Cytoplasmic Antibody-Positive Vasculitis Presenting With Periaortitis and Muscle Vasculitis in a Patient With Chronic Chagas Disease. Scand. J. Rheumatol. 49, 339-340. doi: 10.1080/03009742.2019.1701073

Garcia-Bustos, V., Calabuig, E., López-Aldeguer, J., and Moral Moral, P. (2020b). Authors' Reply. Scand. J. Rheumatol. 49, 342. doi: 10.1080/03009742.2020.1756401

Giordanengo, L., Gea, S., Barbieri, G., and Rabinovich, G. A. (2001). AntiGalectin-1 Autoanti- Bodies in Human Trypanosoma Cruzi Infection: Differential Expression of This $\beta$-Galactoside-Binding Protein in Cardiac Chagas' Disease. Clin. Exp. Immunol. 124, 266-273. doi: 10.1046/j.13652249.2001.01512.x

Girones, N., Carrasco-Marin, E., Cuervo, H., Guerrero, N. A., Sanoja, C., John, S., et al. (2007). Role of Trypanosoma Cruzi Autoreactive T Cells in the Generation of Cardiac Pathology. Ann. N. Y. Acad. Sci. 1107, 434e444. doi: 10.1196/annals.1381.046

Goin, J. C., Borda, E. S., Auger, S., Storino, R., and Sterin-Borda, L. (1999). Cardiac M2 Musca- Rinic Cholinoceptor Activation by Human Chagasic Autoantibodies: Association With Bradycardia. Heart 82, 273-278. doi: 10.1136/hrt.82.3.273

González Cappa, S. M., Sanz, O. P., Muller, L. A., Molina, H. A., Fernández, J., Rimoldi, M. T., et al. (1987). Peripheral Nervous System Damage in Experimental Chronic Chagas' Disease. Am. J. Trop. Med. Hyg. 36, 41-45. doi: 10.4269/ajtmh.1987.36.41

Iwai, L. K., Juliano, M. A., Juliano, L., Kalil, J., and Cunha-Neto, E. (2005). T-Cell Molecular Mimicry in Chagas Disease: Identification and Partial Structural Analysis of Multiple Cross-Reactive Epitopes Between Trypanosoma Cruzi B13 and Cardiac Myosin Heavy Chain. J. Autoimmun. 24, 111-117. doi: 10.1016/j.jaut.2005.01.006

Jiménez, M. A. V., Nascimento, J. H. M., Monnerat, G., Maciel, L., Paiva, C. N., Pedrosa, R. C., et al. (2017). Autoantibodies With Beta-Adrenergic Activity
From Chronic Chagasic Patients Induce Cardiac Arrhythmias and Early Afterdepolarization in a Drug-Induced LQT2 Rabbit Hearts. Int. J. Cardiol. 240, 354-359. doi: 10.1016/j.ijcard.2017.02.066

Kaplan, D., Ferrari, I., Bergami, P. L., Mahler, E., Levitus, G., Chiale, P., et al. (1997). Antibodies to Ribosomal P Proteins of Trypanosoma Cruzi in Chagas Disease Possess Functional Autoreactivity With Heart Tissue and Differ From Anti-P Auto- Antibodies in Lupus. Proc. Natl. Acad. Sci. U. S. A. 94, 1030110306. doi: 10.1073/pnas.94.19.10301

Kierszenbaum, F. (2003). Views on the Autoimmunity Hypothesis for Chagas Disease Pathogenesis. FEMS Immunol. Med. Microbiol. 37, 1-11. doi: 10.1016/ S0928-8244(03)00097-X

Labovsky, V., Smulski, C. R., Gómez, K., Levy, G., and Levin, M. J. (2007). Anti- $\beta 1$ Adrenergic Receptor Autoantibodies in Patients With Chronic Chagas Heart Disease. Clin. Exp. Immunol. 148, 440-449. doi: 10.1111/j.1365-2249.2007.03381.x

Laguens, R. P., Cossio, P. M., Diez, C., Segal, A., Vasquez, C., Kreutzer, E., et al. (1975). Immunopathologic and Morphologic Studies of Skeletal Muscle in Chagas' Disease. Am. J. Pathol. 80, 153-162.

Laucella, S. A., de Titto, E. H., and Segura, E. L. (1996). Epitopes Common to Trypanosoma Cruzi and Mammalian Tissues are Recognized by Sera From Chagas' Disease Patients: Prognosis Value in Chagas Disease. Acta Trop. 62, 151-162. doi: 10.1016/s0001-706x(96)00032-0

Leacy, E., Brady, G., and Little, M. A. (2020). Pathogenesis of ANCA-Associated Vasculitis: An Emerging Role for Immunometabolism. Rheumatol. (Oxf) 59, iii33-iii41. doi: 10.1093/rheumatology/keaa023

Leon, J. S., and Engman, D. M. (2003). “The Contribution of Autoimmunity to Chagas Heart Disease", in American Trypanosomiasis, vol. 7 . Eds. K. M. Tyler and M. A. Miles (Springer, Boston, MA: World Class Parasites). doi: 10.1007/978-1-4419-9206-2_9

Leon, J. S., Godsel, L. M., Wang, K., and Engman, D. M. (2001). Cardiac Myosin Autoimmunity in Acute Chagas' Heart Disease. Infect. Immun. 69, 5643-5649. doi: 10.1128/IAI.69.9.5643-5649.2001

Levin, M. J. (1996). In Chronic Chagas Heart Disease, Don't Forget the Parasite. Parasitol. Today (1996) 12, 415-416. doi: 10.1016/0169-4758(96)20051-1

Medei, E., Pedrosa, R. C., Benchimol Barbosa, P. R., Costa, P. C., Hernández, C. C., Chaves, E. A., et al. (2007). Human Antibodies With Muscarinic Activity Modulate Ventricular Repolarization: Basis for Electrical Disturbance. Int. J. Cardiol. 115, 373-380. doi: 10.1016/j.ijcard.2006.03.022

Mesri, E. A., Levitus, G., Hontebeyrie-Joskowicz, M., Dighiero, G., Van Regenmortel, M. H., and Levin, M. J. (1990). Major Trypanosoma Cruzi Antigenic Determinant in Chagas' Heart Disease Shares Homology With the Systemic Lupus Erythematosus Ribosomal P Protein Epitope. J. Clin. Microbiol. 28, 1219-1224. doi: 10.1128/JCM.28.6.1219-1224.1990

Morrot, A., Terra-Granado, E., Pérez, A. R., Silva-Barbosa, S. D., Milićević, N. M., Farias-de-Oliveira, D. A., et al. (2011). Chagasic Thymic Atrophy Does Not Affect Negative Selection But Results in the Export of Activated CD4+CD8+ T Cells in Severe Forms of Human Disease. PloS Negl. Trop. Dis. 5, e1268. doi: 10.1371/journal.pntd.0001268

Mukherjee, S., Huang, H., Weiss, L. M., Costa, S., Scharfstein, J., and Tanowitz, H. B.. (2003). Role of Vasoactive Mediators in the Pathogenesis of Chagas' Disease. Front. Biosci. 8, e410-e419. doi: 10.2741/1103

Okumura, M., Brito, T., Pereira-da-Silva, L. H., Carvalho-da-Silva, A., and CorreaNeto, A. (1960). The Pathology of Experimental Chagas' Disease in Mice. I. Digestive Tract Changes With Special Reference to Necrotizing Arteritis. Rev. Inst. Med. Trop. São Paulo 2, 17-28.

Ozen, S. (2017). The Changing Face of Polyarteritis Nodosa and Necrotizing Vasculitis. Nat. Rev. Rheumatol. 13, 381-386. doi: 10.1038/nrrheum.2017.68

Ozen, S., and Batu, E. D. (2018). Vasculitis Pathogenesis: Can We Talk About Precision Medicine? Front. Immunol. 9, 1892. doi: 10.3389/fimmu.2018.01892

Passos, L. S. A., Magalhães, L. M. D., Soares, R. P., Marques, A. F., Nunes, M. D. C. P., Gollob, K. J., et al. (2017). Specific Activation of CD4- CD8- DoubleNegative T Cells by Trypanosoma Cruzi-Derived Glycolipids Induces a Proinflammatory Profile Associated With Cardiomyopathy in Chagas Patients. Clin. Exp. Immunol. 190, 122-132. doi: 10.1111/cei.12992

Pérez, A. R., de Meis, J., Rodriguez-Galan, M. C., and Savino, W. (2020). The Thymus in Chagas Disease: Molecular Interactions Involved in Abnormal TCell Migration and Differentiation. Front. Immunol. 11, 1838. doi: 10.3389/ fimmu.2020.01838

Pérez-Molina, J. A., and Molina, I. (2018). Chagas Disease. Lancet 391, 82-94. doi: $10.1016 /$ S0140-6736(17)31612-4 
Petkova, S. B., Huang, H., Factor, S., Pestell, R., Bouzahzah, B., Jelicks, L., et al. (2001). The Role of Endothelin in the Pathogenesis of Chagas' Disease. Int. J. Parasitol. 393, 499-511. doi: 10.1016/s0020-7519(01)00168-0

Petkova, S. B., Tanowitz, H. B., Magazine, H. I., Factor, S. M., Chan, J., Pestell, R. G., et al. (2000). Myocardial Expression of Endothelin-1 in Murine Trypanosoma Cruzi Infection. Cardiovasc. Pathol. 9, 257-265. doi: 10.1016/ s1054-8807(00)00045-4

Prado, C., Jelicks, L., Weiss, L., Factor, S., Tanowitz, H., and Rossi, M. (2011). The Vasculature in Chagas Disease. Adv. Parasitol. 76, 83-99. doi: 10.1016/B978-012-385895-5.00004-9

Retondaro, F. C., Dos Santos Costa, P. C., Pedrosa, R. C., and Kurtenbach, E. (1999). Presence of Antibodies Against the Third Intracellular Loop of the M2 Muscarinic Receptor in the Sera of Chronic Chagasic Patients. FASEB J. 13, 2015-2020. doi: 10.1096/fasebj.13.14.2015

Rizzo, L. V., Cunha-Neto, E., and Teixeira, A. R. (1989). Autoimmunity in Chagas' Disease: Specific Inhibition of Reactivity of CD4p T Cells Against Myosin in Mice Chronically Infected With Trypanosoma Cruzi. Infect. Immun. 57, 2640e2644. doi: 10.1128/iai.57.9.2640-2644.1989

Roffê, E., Marino, A. P. M. P., Weaver, J., Wan, W., de Araújo, F. F., Hoffman, V., et al. (2016). Trypanosoma Cruzi Causes Paralyzing Systemic Necrotizing Vasculitis Driven by Pathogen-Specific Type I Immunity in Mice. Infect. Immun. 84, 1123-1136. doi: 10.1128/IAI.01497-15

Said, G., Joskowicz, M., Barreira, A. A., and Eisen, H. (1985). Neuropathy Associated With Experimental Chagas' Disease. AnnNeurol 18, 676-683. doi: 10.1002/ana.410180609

Santos-Buch, C. A., Acosta, A. M., Zweerink, H. J., Sadigursky, M., Andersen, O. F., von Kreuter, B. F., et al. (1985). Primary Muscle Disease: Definition of a 25$\mathrm{kDa}$ Polypeptide Myopathic Specific Chagas Antigen. Clin. Immunol. Immunopathol. 1985. 37, 334-350. doi: 10.1016/0090-1229(85)90103-5

Shavit, E., Alavi, A., and Sibbald, R. G. (2018). Vasculitis-What Do We Have to Know? A Review of Literature. Int. J. Low Extrem. Wounds 17, 218-226. doi: $10.1177 / 1534734618804982$

Shinjo, S. K., and Bonfá, E. (2011). Cutaneous Vasculitis in Systemic Lupus Erythematosus: Association With Anti-Ribosomal P Protein Antibody and Raynaud Phenomenon. Clin. Rheumatol. 30, 173-177. doi: 10.1007/s10067-010-1432-4

Sunnemark, D., Frostegard, J., Orn, A., and Harris, R. A. (1998). Cellular and Cytokine Characterization of Vascular Inflammation in CBA/J Mice Chronically Infected With Trypanosoma Cruzi. Scand. J. Immunol. 48, 480484. doi: 10.1046/j.1365-3083.1998.00410.x

Tanowitz, H. B., Gumprecht, J. P., Spurr, D., Calderon, T. M., Ventura, M. C., Raventos-Suarez, C., et al. (1992). Cytokine Gene Expression of Endothelial Cells Infected With Trypanosoma Cruzi. J. Infect. Dis. 166, 598-603. doi: 10.1093/infdis/166.3.598

Tanowitz, H. B., Machado, F. S., Jelicks, L. A., Shirani, J., de Carvalho, A. C., Spray, D. C., et al. (2009). Perspectives on Trypanosoma Cruzi-Induced Heart Disease
(Chagas Disease). Prog. Cardiovasc. Dis. 51, 524-539. doi: 10.1016/ j.pcad.2009.02.001

Tarleton, R. L. (2001). Parasite Persistence in the Aetiology of Chagas Disease. Int. J. Parasitol. 31, 550-554. doi: 10.1016/S0020-7519(01)00158-8

Todorov, A. G., Andrade, D., Pesquero, J. B., Araujo Rde, C., Bader, M., Stewart, J., et al. (2003). Trypanosoma Cruzi Induces Edematogenic Responses in Mice and Invades Cardiomyocytes and Endothelial Cells In Vitro by Activating Distinct Kinin Receptor (B1/B2) Subtypes. FASEB J. 17, 73-75. doi: 10.1096/ fj.02-0477fje

Vermelho, A. B., de Meirelles Mde, N., Pereira, M. C., Pohlentz, G., and BarretoBergter, E. (1997). Heart Muscle Cells Share Common Neutral Glycosphingolipids With Trypanosoma Cruzi. Acta Trop. 64, 131-143. doi: 10.1016/s0001-706x(96)00627-4

Vianna, G. (1911). Contribuiçao Para O Estudo Da Anatomia Patológica Da Moléstia De Chagas. Mem. Inst. Oswaldo Cruz 3, 276-294. doi: 10.1590/S007402761911000200004

Weaver, J. D., Hoffman, V. J., Roffe, E., and Murphy, P. M. (2019). Low-Level Parasite Persistence Drives Vasculitis and Myositis in Skeletal Muscle of Mice Chronically Infected With Trypanosoma Cruzi. Infect. Immun. 87, e00081e00019. doi: 10.1128/IAI.00081-19

Wen, J. J., Vyatkina, G., and Garg, N. (2004). Oxidative Damage During Chagasic Cardiomyopathy Development: Role of Mitochondrial Oxidant Release and Inefficient Antioxidant Defense. Free Radic. Biol. Med. 37, 1821-1833. doi: 10.1016/j.freeradbiomed.2004.08.018

World Health Organization (2020). Thirteenth Meeting of the Strategic and Technical Advisory Group for Neglected Tropical Diseases, 17-17 September 2020 ( Geneva, Switzerland: World Health Organization).

World Health Organization (2021) Chagas Disease (Also Known as American Trypanosomiasis). Available at: https://www.who.int/news-room/fact-sheets/ detail/chagas-disease-(american-trypanosomiasis) (Accessed June 13, 2021).

Zhang, L., and Tarleton, R. L. (1999). Parasite Persistence Correlates With Disease Severity and Localization in Chronic Chagas' Disease. J. Infect. Dis. 180, 480e486. doi: 10.1086/314889

Conflict of Interest: The authors declare that the research was conducted in the absence of any commercial or financial relationships that could be construed as a potential conflict of interest.

Copyright (c) 2021 Garcia-Bustos, Moral Moral, Cabañero-Navalon, Salavert Lleti and Calabuig Muñoz. This is an open-access article distributed under the terms of the Creative Commons Attribution License (CC BY). The use, distribution or reproduction in other forums is permitted, provided the original author(s) and the copyright owner(s) are credited and that the original publication in this journal is cited, in accordance with accepted academic practice. No use, distribution or reproduction is permitted which does not comply with these terms. 